\title{
Puerto Rico y migración: una aproximación a través de los cuentos de José Luis González
}

\author{
Puerto Rico and migration: a view through short stories by \\ José Luis González
}

David Rodríguez-Silva ${ }^{1} \&$ Daniela Casas-Sosa ${ }^{2}$

\begin{abstract}
Resumen
En este artículo se analiza una selección de cuentos del escritor José Luis González (1926-1997), caracterizados por tratar el tema de la migración puertorriqueña a mediados del siglo XX. A manera de introducción, damos un panorama general de los antecedentes históricos, sociales y políticos que propiciaron la migración en Puerto Rico. Posteriormente, exponemos y analizamos las causas y consecuencias de dicho fenómeno a nivel interno, es decir, del que ocurrió del campo a las urbes. Con respecto a la migración externa, tratamos tópicos como las condiciones laborales, estabilidad económica, calidad de vida e identidad de los puertorriqueños en los Estados Unidos. Por último, abordamos la discriminación que padecen los inmigrantes en las grandes metrópolis a través del "racismo cultural", concepto que explica la instauración del imaginario de la comunidad puertorriqueña, el cual facilitó la conformación de una fuerza de trabajo barata y a la vez ocultó las verdaderas causas de su marginación en los ámbitos educativo y laboral. Como conclusión damos cuenta de la importancia de estudiar la obra de José Luis González para comprender aspectos del fenómeno de la migración y su impacto, no sólo en el Caribe sino en el mundo en general.
\end{abstract}

Palabras clave: José Luis González; migración; cuento; Puerto Rico; caribe

\begin{abstract}
In this article, an analysis is made of a selection of short stories by Puerto Rican writer José Luis González (19261997), all of them dealing with the theme of Puerto Rican migration at the middle of the 20th century. As an introduction, there is an overview of the historical, social and political background that led to migration in Puerto Rico. Later on, causes and consequences of internal migration, that is to say, from the countryside to the cities, are presented. In the case of external migration, working conditions, economic stability, quality of life and identity of Puerto Ricans in the United States are also discussed. Finally, the discrimination suffered by immigrants in big cities through "cultural racism" - a concept that explains the creation of an imaginary around the Puerto Rican
\end{abstract}

Tipología: Artículo de reflexión

Recibido: 01/04/2016

Evaluado: 21/09/2016

Aceptado: 21/10/2016

Disponible en línea: 01/03/2017

Como citar este artículo: Rodríguez-Silva, D. \& Casas-Sosa, D. (2017). Puerto Rico y migración: una aproximación a través de los cuentos de José Luis González. Jangwa Pana, 16 (1), 122 - 130. Doi: http://dx.doi.org/10.21676/16574923.1962

1. Estudiante de Licenciatura en Lengua y Literaturas Hispánicas. Universidad Nacional Autónoma de México. México. Correo electrónico: dduckrs@ gmail.com. ORCID ID: orcid.org/0000-0001-7361-3914

2. Licenciada en Educación Básica con Énfasis en Humanidades y Lengua Castellana. Universidad Distrital Francisco José de Caldas. Colombia. Correo electrónico: danielala612@gmail.com. ORCID ID: orcid.org/0000-0001-7382-4463 
community, which facilitates the formation of a cheap labor force hiding the true causes of their marginalization in education and employment fields - is addressed. In the conclusion, it is highlighted the importance of studying the works of José Luis González towards an understanding of the aspects that make up the phenomenon of migration and its effects and impact, not only in the Caribbean, but in the world at large.

Keywords: José Luis González; migration; Caribbean short story; Puerto Rico; Caribbean

\section{Introducción}

$E_{1}^{\prime}$ interés por analizar los cuentos de José Luis González (1926-1997) radica en la importancia de su obra, pues esta es un reflejo de los acontecimientos históricos ocurridos en Puerto Rico a mitad del siglo XX. En el presente artículo analizamos los cuentos "En la sombra", "La guardarraya", "Encrucijada", "En el fondo del caño hay un negrito", "La carta", "El pasaje", "En Nueva York" y "La noche que volvimos a ser gente", en los cuales se problematizan las causas y consecuencias del fenómeno de la migración no solo a nivel psicológico, sino también en los planos económico y social. Por estas razones, consideramos necesario que su narrativa sea expuesta y, por consiguiente, difundida a través del presente artículo.

José Luis González se caracterizó por crear textos que revelan a los lectores "los aspectos de la opresión que no son obvios" (González, 1975, p. 161) que suceden cotidianamente. Es por ello que el autor retrata a los distintos sectores de las clases bajas de Puerto Rico, a lo que él llama "la gente pequeña", es decir, al hombre común y corriente (González, 1975, p. 167). De esta forma, obreros, campesinos, pescadores, entre otros representantes de los estratos bajos de la sociedad puertorriqueña desfilan en las no muy numerosas, pero sí contundentes páginas de su producción cuentística. Los personajes que reflejan la condición de los migrantes son los que ocupan este escrito.

La crítica ha incluido a José Luis González en la Generación del 50, junto con René Marqués, Pedro Juan Soto, Emilio Díaz Valcárcel, entre otros. Este grupo de escritores se caracterizó por tratar los problemas del campesinado durante (...) (...)una época histórica de rápidas transformaciones sociales y políticas en el Puerto Rico de mediados de nuestro siglocambios provocados por el reformismo político y social del Partido Popular, la creación del Estado Libre Asociado, la industrialización de la isla, la ruina del sector agrícola y la creciente anexión económica y agresión cultural norteamericana. (Acosta, 1986, p. 220)

Cabe recordar que antes de esta década, el suceso que marcó a la isla durante el siglo $\mathrm{XX}$ fue que a partir del año 1898 dejaron de ser una colonia española para encontrarse luego bajo el dominio del imperio estadounidense (Castillo, 2010). Este momento histórico provocó una situación compleja en diversos ámbitos, pues las distintas tradiciones que ahora convivían en la región (la anglosajona, la hispana y la afroantillana) se vieron obligadas a luchar por un espacio en el panorama cultural y político del país. (González, 1989)

A partir de 1940, la base económica de Puerto Rico comenzó un proceso de transformación, en el cual pasó gradualmente de ser agrícola, con el café y caña como sus principales productos de exportación desde el siglo XVIII, a enfocarse en la actividad industrial, con la instalación de fábricas de botellas, zapatos, cartón y cerámica en las distintas ciudades del país. Lo anterior se llevó a cabo a través de las reformas impulsadas por el Partido Popular Democrático (PPD), cuyas propuestas buscaban mejorar las condiciones sociales y económicas de las clases bajas, lo que le valió el apoyo de los sectores populares e independentistas (Sacarano, 2002).

Entre las iniciativas más importantes del PPD se encuentran la promulgación de la Ley de los 500 
Acres o Ley de Tierras de 1941 y la creación de la Compañía de Fomento Industrial. La primera proponía expropiar las tierras de cultivo, fijando un límite de extensión por propietario, además de "expandir y modernizar la infraestructura, especialmente para llevar luz y agua potable a las zonas rurales del país" (Scarano, 2002, p. 818). En cuanto a la segunda, se encargó de "mejorar la capacidad de las industrias existentes para competir, especialmente en el mercado puertorriqueño" (Scarano, 2002, p. 824), así como de investigar sobre nuevas industrias que pudieran instalarse en la isla.

Las consecuencias no se hicieron esperar: aunque se intentó combatir el latifundismo, la ley no se cumplió al pie de la letra. Aunada a la importación de productos agrícolas de los Estados Unidos, se produjo la ruina del campo, lo que desembocó en una migración masiva a las ciudades puertorriqueñas y de los Estados Unidos, país en donde se requería mano de obra por la ausencia de los trabajadores que se habían enlistado en el ejército durante la Segunda Guerra Mundial. Con respecto a las fábricas creadas hasta 1947, éstas se vendieron a los inversionistas estadounidenses a través del programa "Manos a la obra", el cual los exentaba de pagar al erario puertorriqueño. De esta forma, la industrialización de Puerto Rico propició "el aumento del desempleo y la irrefrenable proletarización de los campesinos" (Rivera, 1982, p. 131).

El programa "Manos a la obra" formó parte del cambio de objetivos del PPD durante la posguerra, etapa en la que sus dirigentes abandonaron definitivamente la idea de la lucha por la independencia. En su lugar, se buscó fortalecer la relación con los Estados Unidos, lo que permitió la inversión privada y, en 1952, la promulgación de la Constitución del Estado Libre Asociado (ELA), año en que, curiosamente, se alcanza "el punto máximo de una fase de intensa emigración hacia Estados Unidos" (Scarano, 2002, p. 810). La instauración del ELA no propuso cambios significativos en la administración de la isla; sin embargo, sirvió a los norteamericanos para "presentarse ante la ONU como prueba fehaciente de que el pueblo puertorriqueño había ejercido su derecho a la autodeterminación" (Maldonado, 1988).

A pesar de la creciente entrada del capital norteamericano, las clases bajas no tuvieron una mejoría significativa, sino que, como se observa en la obra de José Luis González, gran parte de los campesinos no tuvieron otra alternativa que trasladarse a las ciudades de Puerto Rico y los Estados Unidos en busca de una mejor calidad de vida.

\section{Discusión}

\section{Migración interna}

La migración en Puerto Rico sucedió tanto a nivel interno, hacia las ciudades de la isla, como a nivel externo, concentrada en los Estados Unidos, principalmente en Nueva York. Algunos de los factores que propiciaron la migración interna fueron:

La pérdida de miles de empleos agrícolas, tras la decadencia de las empresas tradicionales de exportación (azúcar, tabaco y café); la creación de miles de empleos en los centros urbanos (...) la expansión de las facilidades de vivienda, salud, educación y recreo en las ciudades; y las comunicaciones cada vez más integradoras y eficientes entre la ruralía y las ciudades, sobre todo por conducto de los medios de comunicación masiva (la radio primero, y luego la televisión) solían proyectar hacia los campos imágenes de la vida urbana sumamente atractivas. (Scarano, 2002, p. 58)

En el cuento "En la sombra" González (1992) retrata las condiciones precarias en las que trabajan los campesinos de la isla. Estos personajes gastan la mayor parte de sus sueldos en los exiguos alimentos que les venden Alfredo Fernández y su colega Cunito García, empleados del dueño de las tierras, con un ingreso apenas mejor que el de los agricultores. El análisis de las condiciones de vida de campesinos se presenta cuando el protagonista pasea cerca del rancho en donde residen los pobladores, y observa casas "ladeadas, cayéndose; otras sin ventanas, oscuras como 
cuevas" (González, 1992, p. 55), todas ellas dejando a la vista la desnutrición de las familias y sus respectivos animales domésticos. Tras observar este paisaje marcado por la pobreza, José Luis González reflexiona a través de su personaje sobre la injusticia de que aquellos hombres que dedican su vida y esfuerzo a trabajar la tierra no son dueños de ella, mientras que quien sí lo es, se enriquece a costa de la explotación de los pobladores, sin demostrarles ninguna clase de respeto, al grado de referirse a ellos como "animales". En este cuento, la empatía se plantea como un rasgo esencialmente humano, pues el autor contrasta la capacidad del protagonista de conmoverse ante las injusticias que percibe, con el cinismo del terrateniente, quien, junto con su empleado Cunito García, se muestran incapaces de reparar en la atrocidad de la situación, lo que lleva al personaje a describirlos, a su vez, como animales.

Las condiciones laborales del campo puertorriqueño también se describen en "La guardarraya" y en "Encrucijada" (González, 1992). En el primero de estos cuentos, se denuncian las complicaciones de los campesinos durante el tiempo muerto, época en la que se quedan sin trabajo y, por lo tanto, sin ingresos. En el segundo, se relata la historia de dos amigos que se ven obligados a viajar por toda la isla en busca de un trabajo que les garantice un mejor sueldo, o por lo menos que su salud no esté en constante riesgo. Es así como, después de trabajar en distintos oficios, consiguen empleo en la construcción de una presa: uno en la obra y el otro dinamitando las zonas asignadas. De esta forma, los personajes caen en una situación que ellos encuentran preferible, pero que, en realidad, no dista mucho de las circunstancias de su trabajo anterior.

Por otra parte, en "En el fondo del caño hay un negrito" González (1992) denuncia las consecuencias de la migración interna, a través de las diversas situaciones que sufre una familia de afroantillanos. De esta forma, el autor nos transmite las dificultades a las que se enfrentan tras su desplazamiento, como el esfuerzo que les toma adaptarse a otro estilo de vida y jugar otro rol dentro de la sociedad para obtener el sustento diario. Esta complicada situación es precisamente fruto de su condición de ciudadanos desplazados, lo que les dificulta el acceso a un empleo bien remunerado. En consecuencia, esta familia se ve en la necesidad de encontrar un techo sin importar qué tan adecuado es para vivir; es así como deciden asentarse en un arrabal, tal como se menciona en el siguiente fragmento:
Dos mujeres, de las afortunadas que vivían en tierra firme, sobre el fango endurecido de las márgenes del caño, comentaban:
-Hay que velo. Si me lo bieran contao, biera dicho que era embuste.
-La necesidá, doña. A mí misma, quién me lo biera dicho, que yo diba llegar aquí. Yo que tenía hasta mi tierrita.
-Pues nosotros juimos de los primeros. Casi no bía gente y uno cogía la parte más sequecita, ¿ve? Pero los que llegan ahora, fijese, tienen que tirarse al agua, como quien dice. Pero, bueno y esa gente, ¿de ónde diantre haberán salío?
-A mí me dijieron que por ai por Isla Verde tan orbanisando y han sacao un montón de negros arrimaos. A lo mejor son desos. (González, 1992, p. 185).

Además de describir las condiciones en que viven estos personajes, con el final catártico de esta historia, el autor nos propone la noción de la otredad, representada en el bebé Melodía, quien se lanza inconscientemente a la búsqueda de sí mismo, evadiendo de esta manera el rol que recién desempeñan su padre y madre en una sociedad capitalista mediada por la industria (Díaz, 2005). Asimismo, el acercamiento que propicia González entre el negrito de la superficie y el del reflejo supone un encuentro con el otro, por lo que este cuento es también un llamado a reconocernos en los demás para identificar los rasgos comunes que edifican la idea de un sentir patriótico y nacional, cuya construcción ha sido problematizada históricamente en Puerto Rico.

Un último ejemplo de la condición del migrante dentro de Puerto Rico se encuentra en "La carta" (González, 1992), relato ambientado en San Juan, en 1947, año en que se pone en acción el programa "Manos a la obra". Este relato permite entender las 
expectativas que tienen los desplazados al viajar hacia las ciudades, idea a la que consideran como una oportunidad infalible de mejorar su calidad de vida y la de sus familiares. Esto explica que el protagonista mienta sobre el éxito real que tiene en la urbe a la que ha llegado: Juan narra en la carta que escribe a su madre que ya ha encontrado un trabajo bien remunerado, tanto que ya gana lo mismo que sus conocidos e incluso más. La expectativa que tiene su madre de él es tal que este es incapaz de narrar la cruenta realidad, por lo que sigue prometiendo todos los regalos que ha acordado llevar, a pesar de su verdadera condición:

Después de firmar, dobló cuidadosamente el papel ajado y lleno de borrones y se lo guardó en el bolsillo de la camisa. Caminó hasta la estación de correos más próxima, y al llegar se echó la gorra raída sobre la frente y se acuclilló en el umbral de una de las puertas. Dobló la mano izquierda, fingiéndose manco, y extendió la derecha con la palma hacia arriba.

Cuando reunió los cuatro centavos necesarios, compró el sobre y el sello y despachó la carta.

(González, 1992, p. 149)

La historia de "La carta" es terrible, pues a pesar de padecer la miseria en la ciudad, el protagonista continúa difundiendo entre sus seres queridos la idea de que emigrar es la solución a la pobreza, idea que tal vez él mismo no ha abandonado por completo.

\section{Migración externa}

Con respecto a la migración externa, los datos estadísticos arrojan que entre 1898 y 1944 el total de puertorriqueños movilizados a los Estados Unidos de América no rebasaba la cifra de 90,000. En este periodo de tiempo incluso hubo años en los que el flujo de personas fue inverso, como durante el crack del 29, cuando muchos pobladores retornaron a la isla. A partir de 1944, el reclutamiento militar para las guerras (la Segunda Guerra Mundial, y posteriormente el conflicto en Corea y Vietnam) provocó una baja en el número de obreros en el país del norte, lo que permitió que se ampliara la oferta laboral para los inmigrantes.
Esto propició que entre 1945 y 1949 y entre 1950 y 1959 fueran 135, 000 y 430,000 los emigrados que llegaron a los Estados Unidos provenientes de la isla, respectivamente, de los cuales más del 60 \% tenían de 15 a 39 años de edad (Vázquez, 1963).

No obstante, las estadísticas indican que en estos años la oferta laboral aumentó para los inmigrantes en ciudades como Nueva York, las condiciones de trabajo estaban lejos de ser las mejores, tal como se cuenta en "El pasaje" (González, 1992), en el cual Juan y Jesús se detienen en un bar a platicar sobre su vida en los Estados Unidos. El primero, desencantado, relata su experiencia: los 35 dólares que recibe de sueldo a la semana son insuficientes, además de que su trabajo resulta agotador. El segundo, quien lleva menos tiempo en el país del norte, también ha chocado con la realidad, pues se encuentra desempleado y desesperado a tal grado que añora un empleo aunque sea tan mal pagado como el de su amigo. Sin embargo, su deseo más fuerte es volver a su tierra aun sabiendo que, una vez allí, probablemente su situación no mejore:

-Me rajo, me voy pa Puerto Rico - ¿Pa Puerto Rico? ¿A qué? ¿A picar caña?

- A lo que sea. Esto aquí es la muerte. Yo tengo un cuñao mecánico que trabaja en la General Motors en San Juan. A lo mejor me consigue una pega. (González, 1992, p. 209)

Asimismo, en el cuento "En Nueva York" (González, 1992), a través de una conversación entre Marcelino y un compatriota suyo, nos enteramos de algunas de las actividades laborales en las que comúnmente se desempeñaban los emigrantes puertorriqueños:

- Si me hubieras visto ayer, te hubiera puesto a grabar discos enseguida

- ¿A grabar discos?

- Si chico a lavar platos en una cafetería. Pero ya ese chance lo cogió otro Paisa.

- Ah...

- Pero mira, si quieres meterte en una factoría de ropa te puedo dar la dirección. (p. 176-177)

Marcelino acepta el contacto para trabajar en dicha fábrica, en donde recibe un sueldo muy bajo que no le permite ahorrar y que, además, le 
resulta tan desgastante como a Juan en "El pasaje". El protagonista intenta organizarse con otros empleados por medio de una huelga para exigir la mejora de sus condiciones de trabajo. Sin embargo, el esfuerzo es infructuoso y resulta injustamente despedido por la empresa.

\section{La identidad del migrante y la "comunidad imaginada"}

El fenómeno de la migración es complejo debido a que involucra cuestiones de pertenencia, ya sea a nivel individual o a nivel grupal, por lo que este fenómeno ha puesto en discusión el tema de la identidad nacional en las distintas ciudades donde se ha presentado. Grosfoguel (2007) explica cómo las inmigraciones han cuestionado a las "comunidades imaginadas" de las metrópolis, cuyos miembros generan un sentido de pertenencia entre sí, a pesar de que "no conocerán jamás a la mayoría de sus compatriotas, no los verán, no los oirán siquiera hablar de ellos" (Anderson, 1993, p. 23) pero que en su imaginario forman parte de un grupo en común.

Cuando las poblaciones de inmigrantes se incorporan a las urbes, sufren el rechazo de los ciudadanos residentes debido a que no cumplen con los parámetros que el mito fundacional local ha establecido para considerarlo como parte de la comunidad imaginada, lo que genera tensiones y cuestionamientos sobre las identidades de los grupos que componen a la recién formada población (Grosfoguel, 2007). Esto deriva muchas veces en actitudes racistas como la segregación, que aparta a las poblaciones inmigrantes de las oportunidades laborales y educativas a las que tienen derecho por ser ciudadanos legítimos.

"En Nueva York" ilustra lo anterior: Cuando Marcelino llega a Harlem del Este, se da cuenta de que ese país, hasta hace poco tan extraño, no le parece tan distante en este barrio, puesto que la mayoría de sus habitantes son latinoamericanos. Es así como José Luis González nos transmite el sentir de un inmigrante puertorriqueño en un lugar en donde, aun estando fuera de su país, recuerda su identidad nacional. Al mismo tiempo, el autor nos plantea la idea de la unión que surge entre los individuos que comparten un mismo estilo de vida.

Por otro lado, un ejemplo de la hostilidad que, viven los migrantes por no pertenecer a la comunidad imaginada, está en el cuento "La noche que volvimos a ser gente" (González, 1992). Después de describir su situación laboral, el narrador menciona las bromas que le hacen sus jefes por su condición de migrante: “¿qué, te piensas hacer millonario para poner un casino en Puerto Rico?” (p. 328), ante lo que le responde, de manera igualmente burlona y a través del cliché del consumismo que caracteriza a los estadounidenses, que no, que busca poner una fábrica de humo para vendérsela a los norteamericanos, quienes compran lo que sea siempre y cuando venga enlatado.

Hacia el final del mismo cuento, nos encontramos con un barrio de puertorriqueños, como el de "En Nueva York", ambos ejemplos de la segregación residencial. El protagonista, al llegar al edificio en donde vive y también donde su esposa acaba de dar a luz, se entera de que hay una fiesta en la azotea, a pesar del apagón que ha sufrido la ciudad. Al preguntar a qué se debe dicha celebración, le señalan el cielo, lo que lo hace caer en cuenta de que es una noche estrellada "igual que en Puerto Rico" (González, 1992, p. 339). Si bien la comunidad boricua se encuentra segregada del resto de la población, existe entre ellos un sentido de pertenencia, permeado por la nostalgia que les trae el ser compatriotas y que les ha sido recordado por algo tan sencillo como una noche estrellada, lo que les ha hecho sentirse como personas y no únicamente un engranaje de la gran metrópoli.

\section{Migración y racismo cultural}

Ramón Grosfoguel (2007) propone al racismo como un:

Mecanismo central del mantenimiento de una fuerza trabajadora sin los mismos derechos que los trabajadores blancos. A través del racismo", explica, "se construyó una fuerza de trabajo colonial que servía de mano de obra barata no sólo en las regiones periféricas, sino también en los propios centros metropolitanos" (p. 8). 
acia los años sesentas, debido a esta forma de perpetuar el orden mundial a partir de la división del trabajo, los puertorriqueños son identificados en el imaginario norteamericano como una raza distinta a los negros, blancos, asiáticos y chicanos. Es también por estos años que en los Estados Unidos se deja atrás al "racismo biológico" para dar paso al racismo cultural, en el cual, aunque no se hace uso de la palabra "raza", se discrimina a partir del supuesto de que las minorías son incapaces de convivir con la población original de la metrópoli por sus prácticas culturales, entre las que se encuentran actos antisociales como los delitos, la violencia y las adicciones, actividades que ponen en riesgo al resto de los pobladores (Grosfoguel, 2007). Es decir, las condiciones socioeconómicas originadas por la falta de oportunidades laborales y educativas, materia prima para ascender en la escala social, son consideradas por el discurso oficial como un problema de la cultura de los individuos, lo que desvía la atención de las verdaderas causas de la marginación que padecen. Es así como en el imaginario se considera vagos y criminales a los puertorriqueños, lo cual favorece la marginalización de este grupo en el mercado de trabajo, así como su exclusión en las mejores escuelas públicas, requisito indispensable para ascender en la escala social de los Estados Unidos de la mitad del siglo XX. Esta situación ha causado que los puertorriqueños padezcan:

Una de las tasas de pobreza más altas en los Estados Unidos; la pobreza afecta alrededor de un tercio del total de dicha población $\mathrm{y}$, en algunas ciudades, cerca del $40 \%$ de la población puertorriqueña está por debajo del umbral de la pobreza. (Grosfoguel, 2007, p. 19)

Retomando el análisis de los cuentos, el racismo cultural se retrata en la historia de "En Nueva York": en la conversación que sostienen un par de funcionarios, uno de ellos se refiere a los isleños como "Americans of all of'em, believe or not- conciudadanos todos aunque no lo creas" (González, 1992, p. 174). En esta cita se denuncia la actitud de los norteamericanos al no reconocer a los inmigrantes provenientes de Puerto Rico como ciudadanos estadounidenses, a pesar de que oficialmente lo son, siendo este tipo de comportamientos los que provocan la desigualdad e injusticia en estos sectores de la sociedad.

A su vez, en "La noche que volvimos a ser gente", González (1992) presenta al protagonista reproduciendo los prejuicios inculcados a través del discurso del racismo cultural, pues hace una teoría sobre la supuesta tendencia de los isleños al alcoholismo, en la que supone que estos son viciosos porque el trabajo es tan pesado que no les queda más que pensar en ir a tomar ron después de una jornada laboral. Poco más adelante, el mismo personaje, conocedor de la imagen que tienen los habitantes de la metrópoli sobre los puertorriqueños, siente la mirada inquisidora de los demás cuando Trompoloco se ha detenido a orinar en las vías del subway tras el apagón ocurrido en la ciudad, ante lo que exclamó con alivio: "menos mal que está oscuro y no nos pueden ver la cara, porque si se dan cuenta que somos puertorriqueños..." (p. 334).

En lo que respecta a la falta de oportunidades originadas por la discriminación del racismo cultural, en el cuento "El pasaje" se observa lo siguiente: Jesús no ha podido obtener ni siquiera un empleo de lavaplatos, trabajo que sólo desempeñan los puertorriqueños, dice Juan, pues "ya ni los negros americanos quieren esos trabajos" (González, 1992, p. 208). Esta cita refleja cómo el racismo cultural ha segregado a la comunidad puertorriqueña de las oportunidades de trabajo que tienen con respecto, incluso, de otras minorías, como la afroamericana. La falta de oportunidades orilla a Jesús a cometer un asalto a mano armada, con el que buscaba conseguir dinero para regresar a su país natal y del que únicamente obtuvo ser abatido por la policía.

Una situación parecida le ocurre al protagonista de "En Nueva York", quien, tras ser despedido, cae gravemente enfermo, lo cual lo postra en cama y le impide buscar otro empleo. Tal es la desesperación del personaje que decide cometer un delito: asaltar a la primera persona que encuentre. Marcelino fracasa en su intento de despojar a una mujer 
de sus pertenencias, pero eso no es eso lo que le preocupa, sino que ha caído en cuenta de que ha querido robar a alguien que seguramente ha padecido lo mismo que él.

\section{Conclusiones}

Tal como menciona Souto (1992), José Luis González a través de sus cuentos logra "expresar el mundo del Caribe en su totalidad" (Souto, 1992, p. 11), la cita de Souto es para dar un soporte de la representatividad que tienen los cuentos con respecto a su zona geográfica, y nosotros lo enfocamos a los temas de la injusticia y la pobreza, así como de visibilizar las consecuencias en aquellos quienes las padecen. Por ello consideramos importante la difusión de su producción literaria, pues en ella encontramos constantes denuncias sociales desde una mirada crítica de la realidad, lo que permite al lector comprender las causas de aquellos fenómenos que a simple vista pueden parecerle ajenos.

Con respecto a la migración, cabe resaltar que, aunque es un acto libre puesto que a nadie se le obliga a dejar su lugar de origen, no se puede considerar como un acto voluntario (Vázquez, 1963), sino que son las situaciones sociales y económicas las que orillan a las personas a optar por la migración, tal como se ha demostrado a través del análisis reflexivo y crítico de los cuentos seleccionados.

Una de las problemáticas más graves que sufren las comunidades emigradas es la segregación que los aleja de las oportunidades educativas y laborales. Aunque buena parte de esta discriminación basada en las políticas del racismo cultural provienen de la población residente de las grandes metrópolis, habría que resaltar el papel que ocupa a los gobiernos de estas ciudades, pues esto les garantiza mano de obra barata. Por ello habría que visibilizar el papel que podrían desempeñar los gobiernos de las naciones para velar por los derechos de aquellas personas que han decidido cambiar su lugar de residencia en aras de mejorar las condiciones en que viven ellos y sus familias.
Por lo expuesto en este artículo, afirmamos que los cuentos del autor estudiado son útiles para comprender nuestra realidad, pues, con ellos, el autor brindó a la palabra la tarea de crear mundos posibles, en los cuales es viable transgredir el tiempo y el espacio para reconocernos en lo narrado. Así, el escritor puertorriqueño plantea a la literatura como un compendio de relatos que dan cuenta de los procesos que han modificado nuestras formas de vivir, sentir y relacionarnos, tal como lo han hecho los grandes cuentistas, quienes, desde tiempos inmemoriales, nos han contado la historia de sus pueblos, sin por ello olvidarse de alimentar nuestro espíritu desde la calidad estética de sus narraciones.

\section{Referencias bibliográficas}

Acosta, E. (1986). En torno a la nueva cuentística puertorriqueña. Latin American Research Review, 21, 220-227.

Anderson, B. (1993). Comunidades imaginadas. Reflexiones sobre el origen y la difusión del nacionalismo. México: Fondo de Cultura Económica.

Castillo, G. (2010). La experiencia literaria 'riqueña': cuestiones de migración, lengua e identidad. Lengua y migración, 2 (2), 67-82. Recuperado de: http://lym. linguas.net/Download.axd?type $=$ ArticleItem $\&$ id $=79$

Díaz, L, F. (2005). En el fondo del cano hay un negrito. En Modernidad literaria puertorriqueña (pp. 139166). Puerto Rico: Editores Isla Negra.

González, J, L. (1975). El arte del cuento. En L. Zavala. (Ed.), Teorías del cuento II. La escritura del cuento (pp. 153-174). México: Universidad Nacional Autónoma de México.

González, J, L. (1989). El país de los cuatro pisos. La nave y el puerto. Colección La nave y el puerto, 7, 10-42. Recuperado de: http://www.virginiacolwell. com/wp-content/uploads/2016/01/Pais-de-cuatropisos-1-1.pdf

González, J, L. (1992). Todos los cuentos. México: Universidad Nacional Autónoma de México, Facultad de Filosofía y Letras. 
Grosfoguel, R. (2007). Migrantes coloniales caribeños en los centros metropolitanos del sistema-mundo. Los casos de Estados Unidos, Francia, los Países Bajos y el Reino Unido. Barcelona: CIDOB Ediciones

Maldonado, D, M. (1988). Puerto Rico, una interpretación histórico-social. México: Siglo XXI editores.

Rivera, A. (1982). La realidad puertorriqueña en los cuentos de José Luis González. (Tesis de pregrado). Universidad Nacional Autónoma de México, México.
Souto, A. (1992). Prólogo. En J. González. (Ed.), Todos los cuentos (pp. 7-16). México: Universidad Nacional Autónoma de México, Facultad de Filosofía y Letras.

Vázquez, J. L. (1963). La emigración puertorriqueña ¿solución o problema? Revista de Ciencias Sociales, 7 (4), 323-332. Recuperado de: http://soph.md.rcm. upr.edu/demo/images/VazquezCalzada/Vazquestrabajos/Vazquez-1963La\%20emigracion\%20puertoriquena $\% 20$ solucion $\% 20 \mathrm{o} \% 20$ problema.pdf

Scarano, F. A. (2002). Puerto Rico, Cinco siglos de historia. México: McGrawHill. 